\title{
Effect of Transient Acid Spikes on Developmental Stages of Lepomis Fishes
}

\author{
William G. Hagar, Quan Xu, John P. Ebersole \\ Department of Biology, University of Massachusetts Boston, Boston, USA \\ Email:william.hagar@umb.edu,quan_xu88@yahoo.com,john.ebersole@umb.edu
}

How to cite this paper: Hagar, W.G., $\mathrm{Xu}$ Q. and Ebersole, J.P. (2017) Effect of Transient Acid Spikes on Developmental Stages of Lepomis Fishes. Journal of Water Resource and Protection, 9, 1391-1402. https://doi.org/10.4236/jwarp.2017.912089

Received: August 9, 2017

Accepted: November 20, 2017

Published: November 23, 2017

Copyright $\odot 2017$ by authors and Scientific Research Publishing Inc. This work is licensed under the Creative Commons Attribution International License (CC BY 4.0).

http://creativecommons.org/licenses/by/4.0/

(c) (i) Open Access

\begin{abstract}
The effects of transient acid spikes on development of Lepomis sunfish were studied by combining field work with laboratory studies. Lepomis sunfish eggs were collected from rocks on nests in two freshwater ponds and tested for their resistance to laboratory induced transient acid spikes. Fertilized eggs on rocks within the same nest were used for each $\mathrm{pH}$ transient experiment. Egg masses on one rock from the nest were used as a control while egg masses on another rock were exposed to transient acid spikes. Various stages of development showed different responses to the acidic effects. The major stages studied were fertilized egg, hatched with attached yolk sac, and free swimming with gills. The acid sensitivity followed development stages with the most acid sensitive stage being free swimming with gills. This fieldwork-laboratory data chain supports earlier field studies, providing the final link in an evidentiary chain showing the effects of transient acid spikes on Lepomis hatching profiles in freshwater ponds.
\end{abstract}

\section{Keywords}

Episodic Acid, pH, Lepomis, Sunfishes, Life Stage

\section{Introduction}

There is a developmental sensitivity to $\mathrm{pH}$ for most aquatic organisms. Ocean acidification due to increasing amounts of carbon dioxide is a current and future problem for organisms with the gradual lowering of the ocean $\mathrm{pH}$ [1]. Carbon dioxide increases also can affect freshwater systems, but episodic acidity causes more problems with organisms in poorly buffered streams, ponds and lakes. Although, there has been a general reduction in the overall extent of acidic precipitation from several decades ago, episodic acidification of aquatic environments still remains a substantial threat to aquatic wildlife [2] [3] [4]. Many studies have 
shown that acidified waters are biologically impoverished in some ways [e.g. [5]-[10]]. Effects of sudden anthropogenic inputs producing prolonged acid conditions have been studied [e.g. [11] [12] [13]] as well as field manipulations demonstrating the biological damage caused by acid conditions [e.g., [14] [15] [16] [17] [18]], although it is not clear whether the damage results mainly from the $\mathrm{pH}$ changes or mainly from heavy metals (principally aluminum) that are washed from nearby soil by acid rain [19]. However, studies showing population-level effects of ongoing, routine (though likely anthropogenic) acid input are rare [19] [20].

Studies in our lab employing age-analysis of sagittal otoliths and environmental data loggers have linked abnormalities in age structure of Lepomis sunfishes in Massachusetts ponds to poor buffering capacity [21] and to episodic acid spikes [22] [23]. A critical finding in the evidentiary chain developed through these studies was the under-representation of day-classes that experienced a transient acid spike while undergoing "swim-up", the transition from the yolk-feeding larval form to a juvenile form dependent on gills and a functioning digestive system. Our assumption that the "swim-up" stage of development is especially vulnerable to the effects of acid conditions is therefore critical to our understanding of how episodic acidity impacts Lepomis populations. To verify this key assumption, and to characterize the sensitivity of early life stages of $L e$ pomis sunfishes to acidity, we exposed sunfish eggs, pre-swim-up larvae and post-swim-up fry to acidified pond water in laboratory conditions.

\section{Methods}

\subsection{Study Organism}

The small- to-medium-bodied fishes comprising the speciose Lepomis genus in the perch family (Centrarchidae) are found in most freshwater United States ponds and streams east of the great deserts, and are often important forage for larger game fishes [24] [25]. We studied two Lepomis species, Bluegill (L. macrochirus) and Pumpkinseed (L. gibbosus), that are common in ponds in southeastern Massachusetts. Both species are locally variable and the two species sometimes hybridize [26] [27] and although adults of the two species are readily distinguishable, larvae are nearly identical [28]. In addition, individuals do not take up their species-specific dietary niches until the second year of life [29], so bluegills and pumpkinseeds are both morphologically and ecologically indistinguishable in the early stages of life (i.e., they don't differ as eggs, pre-swim-up larvae, or post-swim-up fry).

Although adult Lepomis sunfishes are hardy and acid-tolerant [30], they build nests in shallow sunlit waters near pond edges where eggs and fry are likely to be exposed to episodic acid spikes caused by run-off during spring rainstorms, as has been documented by Stallsmith et al. [22]. Male sunfishes beat their tails vigorously to clear organic debris from patches of pond bottom, and females lay 
adherent eggs on rocks in the centers of these nests.

\subsection{Field Collection}

To get the early life stage Lepomis needed for our episodic acidification lab experiments, we picked up the moderately large rocks $(1-5 \mathrm{~cm}$ diameter) with adhering eggs from the center of sunfish nests in Maquan Pond, Bristol County, Massachusetts. At the $1 \mathrm{~m}$ depth of our collections, eggs on the rocks are easy to see because they develop a yellow color soon after fertilization; to standardize egg age we did not collect clear eggs (very young) or darker eggs (older and showing the developing eyes). We identified the species of eggs on the rocks by identifying the species of the male sunfish guarding the nest, and safe handling of the eggs was easy because only the rocks had to be touched and moved. Rocks from the same nest were stored and transported in individual containers.

\subsection{Test Procedures}

In the laboratory, we used a dissecting microscope to count the number of eggs on each rock, and then allotted rocks into different life-stage/pH/exposure-duration treatments. To examine the effects of different levels of acidity for different durations on three early-life-stages, the individuals associated with a particular nest rock were exposed as eggs or as pre-swim-up larvae or as post-swim-up fry to a particular acidity $(\mathrm{pH}=4.0,4.5,5.0,5.9)$-with $\mathrm{pH}=5.9$ used as a control since the typical average acidity of Maquan Pond on days without rainstorms was 5.9 [31]. Exposure to the simulated "acid spike" could last for $0,3,12$ or 24 hours-which covers the range of duration of transient acid spikes we have observed in Maquan Pond [22]. The leachates from soils that might appear in a pond experiencing a drop in $\mathrm{pH}$ were not present in any treatments.

The $\mathrm{pH}$ in $500 \mathrm{cc}$ test containers, measured with an Orion $720 \mathrm{pH}$ meter, was established before eggs, larvae, or fry were introduced and then maintained using $0.2 \%$ sulfuric acid and $0.2 \%$ sodium hydroxide; no additional buffers were used. During the tests, $\mathrm{pH}$ was measured at 15 minute intervals and adjusted if necessary. Fluctuations of $\mathrm{pH}$ were within 0.02 above or below desired levels.

Following exposure to acid, the number of survivors in each was counted at 6 hour intervals for several times until it reached a constant; survivors in "no acid" control groups, which had very low mortality, were counted once a day. Test organisms were kept in natural Maquan Pond water $(\mathrm{pH}=5.9)$ before and after their periods of exposure to acid, and dead fish were counted and removed as soon as possible to maintain water quality. All experiments were conducted in a laboratory with constant room temperature $\left(18^{\circ} \mathrm{C}\right)$ and $12 \mathrm{~L}: 12 \mathrm{D}$ illumination schedule.

The experimental design is not fully factorial: some treatment combinations are not represented; since we were assigning rocks rather than individuals to different treatments, sample sizes were not equal, but we made sure that a substantial number of rocks from each nest were placed in control treatments (no acid). 


\subsection{Analysis}

All data were first cast into a MicroSoft ExCel 2007 spreadsheet which was used to calculate basic descriptive statistics (e.g., sample sizes, sample means, and sample standard deviations). With log-transformed survival percentage as the response variable, four-way Analyses of Variance and subsequent paired comparisons in the SYSTAT 11 package were used to determine whether survival was effected by four independent variables: $\mathrm{pH}$, duration of acid exposure, life stage (eggs vs pre-swim-up larvae vs post-swim-up fry), and species (bluegill vs pumpkinseed).

\section{Results}

Overall, 3163 early-life-stage Lepomis individuals (2459 eggs, 309 pre-swim-up larvae, and 395 Post-Swim-Up fry) taken from seven different nests were exposed to acid conditions in these experiments; another 1592 control individuals from the same nests were grown to the Post-Swim-Up stage in non-acid conditions. Survival was high in the controls (94.0\%); survival for groups exposed to acid water ranged from $85.5 \%$ to $0 \%$ (data pooled for groups with the same $\mathrm{pH}$, duration of acid exposure, and life-stage). Roughly 75 per cent of the individuals used in this study were bluegills (L. macrochirus) and the remainder was pumpkinseeds (L. gibbosus).

Four-way Analysis of Variance to determine the effect on survival (angular transform of per cent that survived) of species, life-stage, acidity ( $\mathrm{pH})$, and duration of exposure to acid, showed no difference in survival of bluegills versus pumpkinseeds $(\mathrm{p}=0.274)$. Since survival of these closely related species did not differ, results for pumpkinseeds and bluegills were pooled for subsequent analyses. The other three variables-life-stage, acidity $(\mathrm{pH})$, and duration of exposure-had statistically significant effects (all $\mathrm{p}<0.003$; Table 1 ).

Notably, acidity alone-without attendant heavy metal leachate from soils that might occur in a pond-produced substantial and statistically significant reductions in survival (Table 1; Figure 1). Lower $\mathrm{pH}$ produces more mortality $(\mathrm{p}=$ $0.002)$, and mortality also increases with longer exposure $(\mathrm{p}=0.000)$. Although acidity reduced survival for all three early life stages, all stages did not suffer

Table 1. ANOVA table for the effects of species (levels = L. gibbosus, L. macrochirus), life-stage (levels = Egg, Pre-Swim-Up, Post-Swim-Up), pH (levels = 4.0, 4.5, 5.0, 5.9), and duration of acid exposure (levels $=3,6,12,24 \mathrm{hrs}$ ) on survival of Lepomis in the laboratory.

\begin{tabular}{cccccc}
\hline Source & Sum-of-Squares & $\mathrm{df}$ & Mean Square & F-ratio & $\mathrm{P}$ \\
\hline SPECIES & 0.135 & 1 & 0.135 & 1.220 & 0.274 \\
LIFE-STAGE & 3.218 & 2 & 1.609 & 14.518 & 0.000 \\
PH & 1.901 & 3 & 0.634 & 5.719 & 0.002 \\
DURATION & 2.668 & 3 & 0.889 & 8.024 & 0.000 \\
Error & 6.539 & 59 & 0.111 & & \\
\hline
\end{tabular}




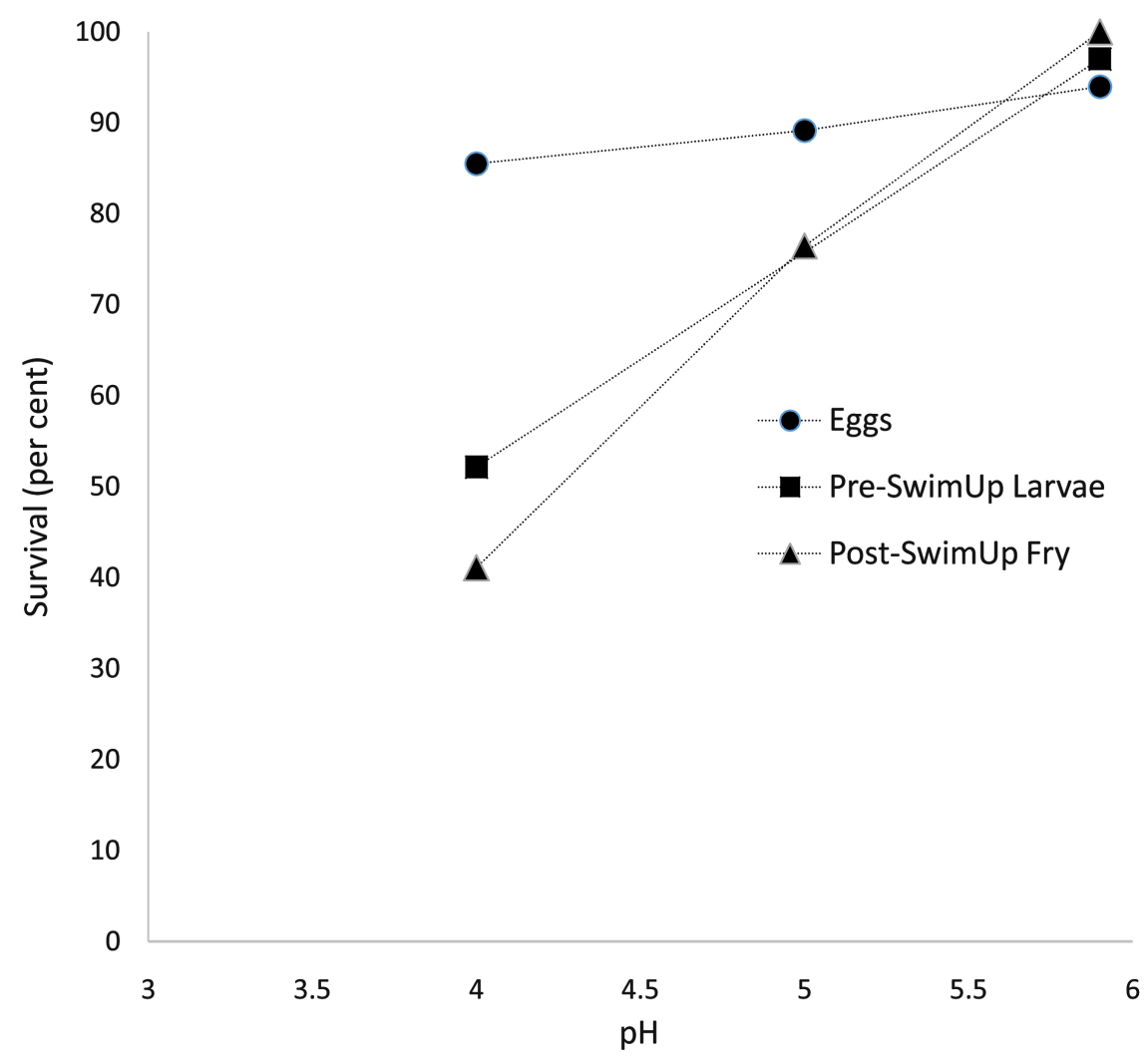

Figure 1. Mean Per cent survival after 6 hours of exposure to prevailing natural water $(\mathrm{pH}=5.9)$ and to acidic water for Lepomis Eggs $(\mathrm{pH}=4, \mathrm{pH}=5)$, Pre-Swim-Up Fry $(\mathrm{pH}=4)$, and Post-Swim-Up Fry $(\mathrm{pH}=4, \mathrm{pH}=5)$. Error bars are lacking because they are too small to be visible on a graph at this scale. Note that the point at the far right is the "prevailing natural $\mathrm{pH}$ control" for all three life stages.

equally $(\mathrm{p}=0.000)$.

To examine the relationship between life-stage and vulnerability more closely, we used a 2-way ANOVA to analyze the effects of life-stage (3 levels) and duration of exposure to acid (4 levels) at $\mathrm{pH}=4$ (Table 2, Figure 2). A non-significant interaction term indicates that all three life stages responded to the combining of acid severity and acid duration in the same way (interaction $\mathrm{p}=0.533$ ), with higher mortality at longer exposures $(p=0.001)$; Post-Swim-Up fry seem to experience the highest mortality, while Eggs appear to be least vulnerable. In fact, the vulnerability of the Post-Swim-Up stage to low $\mathrm{pH}$ puts this life stage in a category by itself. Pairwise statistical testing, with Bonferroni adjustments for multiple comparisons, show that survival was significantly lower for Post-Swim-Up fry than for Eggs ( $p=0.000)$ or Pre-Swim-Up larvae $(p=0.008)$, but the survival of Pre-Swim-Up larvae was not significantly lower than survival of Eggs ( $p=$ $0.187)$.

Exposure to various levels of acidity for different lengths of time showed that Post-Swim-Up fry incur high mortality across a wide range of acid conditions. Although 77 per cent of Post-Swim-Up fry survived 6 hours of exposure to water at $\mathrm{pH}=5$, at $\mathrm{pH}=4$ less than 40 per cent of Post-Swim-Ups survived six hours 
Table 2. ANOVA table for the effects of life-stage (Egg, Pre-Swim-Up, Post-Swim-Up), duration of exposure to $\mathrm{pH} 4$ water $(3,6,12,24 \mathrm{hrs})$, and life-stage/duration interaction on survival of Lepomis in the laboratory.

\begin{tabular}{cccccc}
\hline Source & Sum-of-Squares & df & Mean Square & F-ratio & P \\
\hline STAGE & 3.188 & 2 & 1.594 & 13.395 & 0.000 \\
DURATION & 2.213 & 3 & 0.738 & 6.202 & 0.001 \\
STAGE`DURATION & 0.611 & 6 & 0.102 & 0.857 & 0.533 \\
Error & 5.433 & 46 & 0.119 & & \\
\hline
\end{tabular}

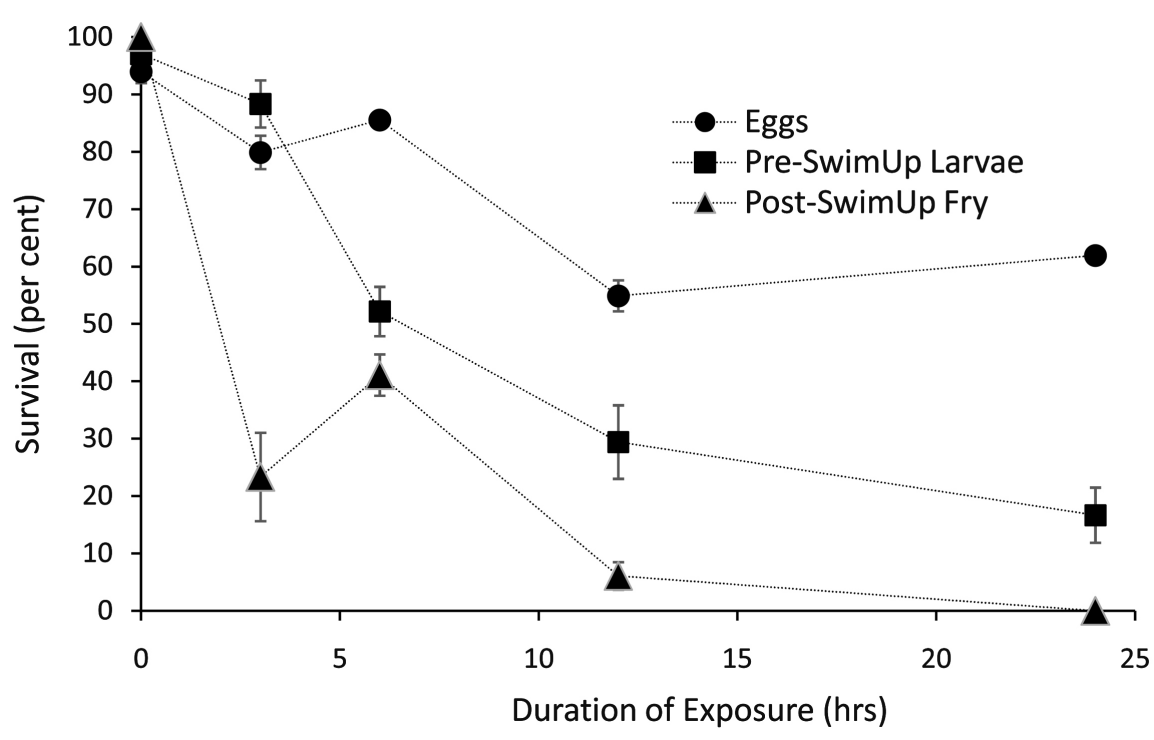

Figure 2. Mean Per cent survival after exposure to acid water $(\mathrm{pH}=4)$ for varying lengths of time (0, 3, 6, 12, and 24 hrs) of Eggs, Pre-Swim-Up Larvae and Post-Swim-Up Fry. Error bars (standard errors) are lacking when they are too small to be visible on a graph at this scale. Note that the point at the far left is the "prevailing natural pH control" for all three life stages.

of exposure-and less than 10 per cent survived 12 hours (Figure 3). Following heavy rainstorms, we have measured acid events of comparable intensity and duration in the shallow breeding area where the experimental organisms were collected.

\section{Discussion}

The biological effects of acidic events have been attributed to low $\mathrm{pH}$ per se and also to the heavy metals, especially Aluminum, that acid rain washes out from the soil [32]. Malcolm et al. [33] found that the concentration of labile aluminum was the best predictor of the presence of brown trout (Salmo trutta) fry for 22 sites in the UK that had been monitored for 22 years. Evidence from many sources indicates that acid and aluminum are an especially toxic combination. Duis \& Oberemm [11] found that long-term exposures to very low $\mathrm{pH}$ and high heavy metal concentrations produced very high levels of mortality in pike (Esox lucius), Delonay et al. [34] found that smaller increases in acidity led to significant 


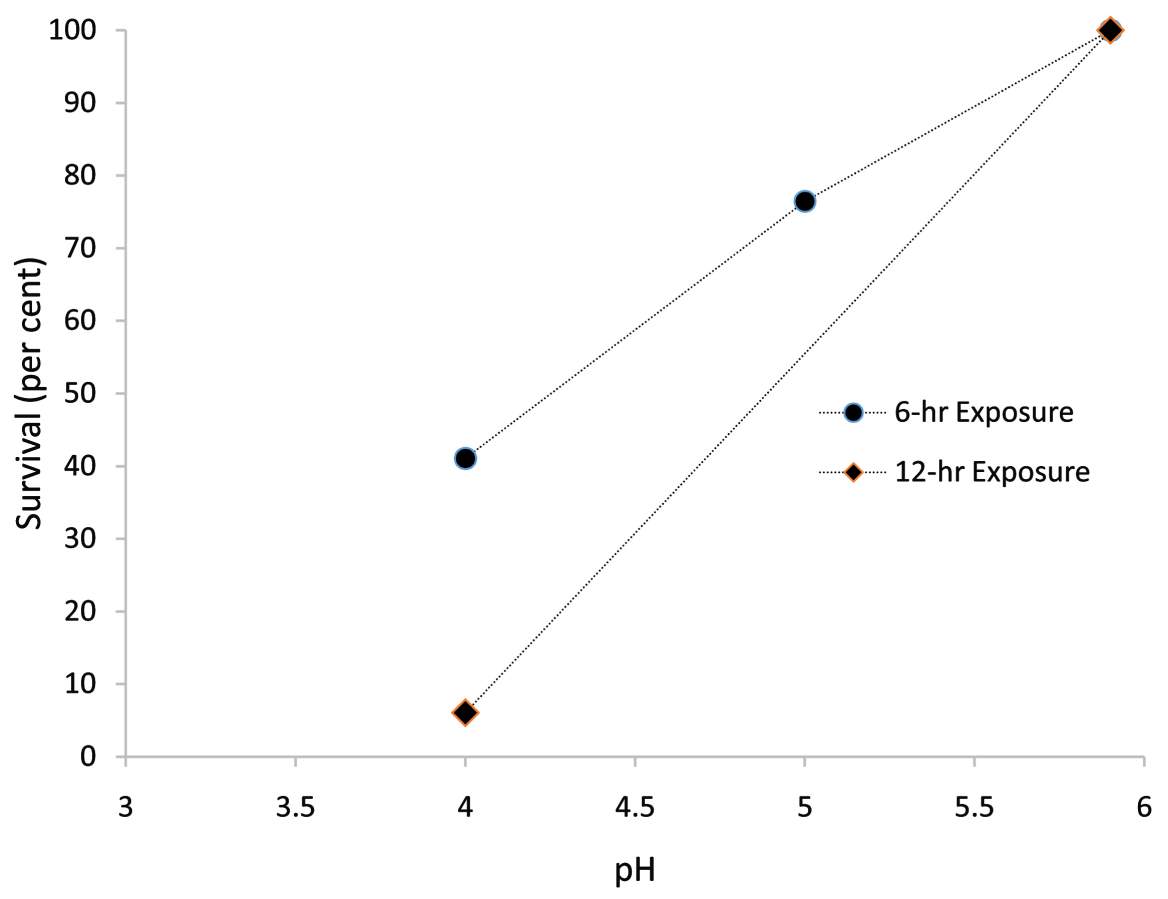

Figure 3. Mean Per cent survival of Lepomis Post-Swim-Up Fry following exposure to prevailing natural water $(\mathrm{pH}=5.9)$ and to acidic water for 6 hours at $\mathrm{pH}=4$ and $\mathrm{pH}=5$, and for 12 hours at $\mathrm{pH}=4$. Prevailing natural $\mathrm{pH}=5.9$. Standard errors are lacking because standard errors are too small to be visible on a graph at this scale. Note that the point at the far right is the "no exposure to acid" control.

mortality of early-life-stage golden trout (Onchorhyncus aguabonita) when aluminum was also added, and Ormerod et al. [35] found that adding aluminum and acid to a Welsh stream increased the mortality of salmonids by at least a factor of five, compared to acid alone. Palmer et al. [30] found in laboratory toxicity tests that adult bluegills (Lepomis macrochirus) were also killed after 4 days of exposure-but only with both very high concentrations of aluminum concentration and very low $\mathrm{pH}$. Our study does not resolve the issue of whether the effects of $\mathrm{pH}$ versus aluminum are stronger, but it establishes that brief exposure to low $\mathrm{pH}$ alone can produce substantial mortality in early life stages of sunfishes.

In addition, our results are consistent with those of Bil'ko [36], who found that brief exposure to low $\mathrm{pH}$ killed eggs of roach (Rutilus rutilus) and bream (Abramis brama). Jellyman \& Harding [37] also found that while 14 days of exposure to $\mathrm{pH} 4.5$ did not affect survival of adults of five New Zealand fishes ((redfin bully Gobiomorphus huttoni, inanga Galaxias maculatus, brown trout Salmo trutta, longfin eel Anguilla dieffenbachii and koaro Galaxias brevipinnis), larval koaro incurred substantial mortality after just 3 days. Malcolm et al. [33] also found in brown trout ( $S$. trutta) that fry were more sensitive than parr to hydrochemical conditions in headwater streams recovering from acidification. Unlike Geffen [38], who found that reducing $\mathrm{pH}$ for two days does not by itself effect mortality of rainbow smelt eggs (Osmerus mordax), we found that acid exposure by itself did cause mortality of Lepomis eggs, but less mortality than in 
the other early life stages. Our laboratory experiments verify that transient acid spikes that are commonly associated with rainfall can produce recruitment failure of sunfishes on a day-class scale.

In a review of the effects of acidification on developing fishes, Sayer et al. [39] noted the heightened vulnerability associated with swim-up: "There is a great increase in vulnerability once dependence on the yolk has come to an end. This period coincides with the movement from the incubation site in the substratum into the open water, where the relevant water chemistry is likely to fluctuate between greater extremes. In waters where acidification is most likely to occur, the early life stages of many freshwater fish species will be close to their survival threshold and only a slight decline in water quality might result in the loss of a complete year class..." By examining sunfishes at several different scales, we have confirmed this prediction. Our finding that post-swim-up fry are significantly more likely to be killed by transient exposure to acidity than other life stages is consistent with the findings of Reader et al. [40] and Serrano et al. [41] that brown trout (Salmo trutta) become much more susceptible to episodic exposure to acid plus aluminum after the yolk-sac has been absorbed.

Most importantly, this finding completes the evidence showing that the episodic $\mathrm{pH}$ changes produced by acid rainstorms cause biological damage, by corroborating the conclusion of Stallsmith et al. [22] that day-class gaps in the age distribution of young-of-the-year Lepomis collected at Maquan Pond in Plymouth County, MA resulted from the mortality inflicted on Post-Swim-Up fry by transient acid spikes $(\mathrm{pH}<5.3)$ associated with rainstorms during the years 1990-1992. They found that day-class gaps were significantly associated with the occurrence of acid spikes when the day-class was at Swim-up (Table 3 presents

Table 3. Data of Stallsmith et al. (1996) presented in four contingency tables (transient acid spikes $\mathrm{X}$ day-class gaps) expressing the association between exposure of Post-Swim-Up fry to transient acid spikes and the under-representation of the exposed day-class in the distribution of young-of-the-year individuals). Values for $\chi^{2}$ and $\mathrm{P}$ are for chi-square tests of homogeneity, using the Yates correction each of the four tests: 1990, 1991, 1992, and all three years combined.

\begin{tabular}{|c|c|c|c|c|c|c|}
\hline Year & & Acid Spike & No Acid Spike & Total & $\chi^{2}$ & $\mathrm{P}$ \\
\hline \multicolumn{7}{|l|}{1990} \\
\hline & Day-class Gap & 7 & 5 & 12 & 4.69 & 0.018 \\
\hline & No Day-Class Gap & 3 & 17 & 20 & & \\
\hline \multicolumn{7}{|l|}{1991} \\
\hline & Day-class Gap & 0 & 4 & 4 & 0.01 & $>0.50$ \\
\hline & No Day-class Gap & 0 & 12 & 12 & & \\
\hline \multicolumn{7}{|l|}{1992} \\
\hline & Day-class Gap & 3 & 2 & 5 & 4.40 & 0.021 \\
\hline & No Day-class Gap & 1 & 16 & 17 & & \\
\hline \multicolumn{7}{|c|}{ 1990-1992 TOTAL } \\
\hline & Day-class Gap & 10 & 11 & 21 & 11.94 & 0.000 \\
\hline & No Day-class Gap & 4 & 45 & 49 & & \\
\hline
\end{tabular}


these data as an erratum to a misprinting in the 1996 report).

\section{Conclusion}

In the Lepomis sunfishes of Plymouth County, otolith studies revealed under-represented year-classes in poorly buffered ponds [21]. Otolith studies on young-of-the-year sunfishes revealed poor recruitment of day-classes associated with transient acid spikes during Swim-Up [22], and the present study links the recruitment failures of day-classes to the high mortality of Swim-Up individuals exposed to acid in controlled conditions. Based on year-to-year associations between acidic inputs and year-class abundances, Hudd [19] has also inferred that episodic acidification produces reduced recruitment of estuarine fishes (burbot $\{$ Lota lota\}, perch $\{$ Perca fluviatilis\}, and smelt $\{$ Osmerus eperlanus\}). For our case of pond-living sunfishes, a complete inferential chain of causation has been established-from transient acid spikes to population abnormalities in age structure indicating recruitment failure-before the biological effects of acid conditions seriously reduced or eliminated the populations.

\section{Acknowledgements}

We thank the University of Massachusetts Boston for Healy Grants that supported these experiments. We thank Bruce Stallsmith, Michael Cutler, and Jerimiah Jarrett for support and helpful discussions with this paper. We thank the reviewers for their suggestions to improve this publication.

\section{References}

[1] Frommel, A.Y., Maneja, R., Lowe, D., Pascoe, C.K., Geffen, A.J. Folkvord, A., Piatkowski, U. and Clemmesen, C. (2014) Organ damage in Atlantic Herring Larvae as a Result of Ocean Acidification. Ecological Applications, 24, 1131-1143. https://doi.org/10.1890/13-0297.1

[2] Lawrence, G.B. (2002) Persistent Episodic Acidification of Streams Linked to Acid Rain Effects on Soil. Atmospheric Environmentm, 36, 1589-1598. https://doi.org/10.1016/S1352-2310(02)00081-X

[3] Lacoul, P., Freedman, B. and Clair, T. (2011) Effects of Acidification on Aquatic Biota in Atlantic Canada. Environmental Reviews, 19, 429-460.

https://doi.org/10.1139/a11-016

[4] Dunford R.W., Donoghue, D.N.M. and Burt, T.P. (2012) Forest Land Cover Continues to Exacerbate Freshwater Acidification Despite Decline in Sulphate Emissions. Environmental Pollution, 167, 58-69. https://doi.org/10.1016/j.envpol.2012.03.022

[5] Beamish R.J. and Harvey, H.H. (1972) Acidification of the La Cloche Mountain Lakes, Ontario and Resulting Fish Mortalities. Journal of the Fisheries Research Board of Canada, 29, 1131-1143. https://doi.org/10.1139/f72-169

[6] Baker, J.P., Warren-Hicks, W.J., Gallagher, J. and Christensen, S.W. (1993) Fish Population Losses from Adirondack Lakes: The Role of Surface Water Acidity and Acidification. Water Resources Research, 29, 861-874.

https://doi.org/10.1029/92WR02329 
[7] Heard, R.M., Sharpe, W.E., Carline, R.F. and Kimmel, W.G. (1997) Episodic Acidification and Changes in Fish Diversity in Pennsylvania Headwater Streams. Transactions of the American Fisheries Society, 126, 977-984. https://doi.org/10.1577/1548-8659(1997)126<0977:EAACIF>2.3.CO;2

[8] Hesthagen, T. and Jonsson, B. (2002) Life History Characteristics of Brown Trout in Lakes at Different Stages of Acidification. Journal of Fish Biology, 60, 415-426. https://doi.org/10.1111/j.1095-8649.2002.tb00290.x

[9] Seiler, S.M. and Turner, A.M. (2004) Growth and Population Size of Crayfish in Headwater Streams: Individual- and Higher-Level Consequences of Acidification, Freshwater Biology, 49, 870-881. https://doi.org/10.1111/j.1365-2427.2004.01231.x

[10] Hünken, A. and Mutz, M. (2007) On the Ecology of the Filter-Feeding Neureclipsis bimaculata (Trichoptera, Polycentropodidae) in an Acid and Iron Rich Post-Mining Stream. Hydrobiologia, 592, 135-150. https://doi.org/10.1007/s10750-007-0735-1

[11] Duis, K. and Oberemm, A. (2000) Survival and Sublethal Responses of Early Life Stages of Pike Exposed to Low $\mathrm{pH}$ in Artificial Post-Mining Lake Water. Journal of Fish Biology, 57, 597-613. https://doi.org/10.1111/j.1095-8649.2000.tb00263.x

[12] Baldigo, B.P., Murdoch, P.S. and Burns, D.A. (2006) Stream Acidification and Mortality of Brook Trout (Salvelinus fontinalis) in Response to Timber Harvest in Catskill Mountain Watersheds, New York, USA. Canadian Journal of Fisheries and Aquatic Sciences, 62, 1168-1183. https://doi.org/10.1139/f05-022

[13] Stephens, F.J. and Ingram, M. (2006) Two Cases of Fish Mortality in Low pH, Aluminium Rich Water. Journal of Fish Diseases, 29, 765-770. https://doi.org/10.1111/j.1365-2761.2006.00772.x

[14] Schindler, K.W., Mills, K.H., Malley, D.F., Findlay, D.I., Shearer, J.A., Davies, I.J., Turner, M.A., Linsey, G.A. and Cruikshank, D.R. (1985) Long-Term Ecosystem Stress: The Effects of Years of Acidification on a Small Lake. Science, 228, 1395-1401. https://doi.org/10.1126/science.228.4706.1395

[15] Watras, C.J. and Frost, T.M. (1989) Little Rock Lake, Wisconsin: Perspective on an Experimental Ecosystem Approach to Acidification. Archives of Environmental Contamination and Toxicology, 18, 157-165. https://doi.org/10.1007/BF01056200

[16] Webster, K.B., Frost, T.M., Watras, C.J., Swenson, W.A., Gonzalez, M. and Garrison, P.J. (1992) Complex Biological Responses to the Experimental Acidification of Little Rock Lake, Wisconsin, USA. Environmental Pollution, 78, 73-78. https://doi.org/10.1016/0269-7491(92)90012-Y

[17] Mills, K.H., Chalanchuk, S.M. and Allan, D.J. (2000) Recovery of Fish Populations in Lake 223 from Experimental Acidification. Canadian Journal of Fisheries and Aquatic Science, 57, 192-204. https://doi.org/10.1139/f99-186

[18] Lachance, S., Berube, P. and Lemieux, M. (2000) In Situ Survival and Growth of Three Brook Trout (Salvelinus fontinalis) Strains Subjected to Acid Conditions of Anthropogenic Origin at the Egg and Fingerling Stages. Canadian Journal of Fisheries and Aquatic Science, 57, 1562-1573. https://doi.org/10.1139/f00-089

[19] Hudd, R. (2000) Springtime Episodic Acidification as a Regulatory Factor of Estuary Spawning Fish Recruitment. Ph.D. Dissertation, University of Helsinki, Helsin$\mathrm{ki}$.

[20] Warren, D.R., Sebestyen, S.D., Josephson, D.C., Lepak, J.M. and Kraft, C.E. (2005) Acidic Groundwater Discharge and In Situ Egg Survival in Redds of Lake-Spawning Brook Trout. Transactions of the American Fisheries Society, 134, 1193-1201.

https://doi.org/10.1577/T04-180.1 
[21] Jarrett, J.N., Cutler, M.B., Ebersole, J.P. and Hagar, W.G. (1993) Seasonal Variation in $\mathrm{pH}$ and Alkalinity and Recruitment of Sunfish Populations. Freshwater Biology, 30, 409-417. https://doi.org/10.1111/j.1365-2427.1993.tb00824.x

[22] Stallsmith, B.W., Ebersole, J.P. and Hagar, W.G. (1996) Differences in Lepomis Sunfish Young-of-the-Year Growth Patterns over Three Years in Two Ponds of Different Buffering Capacity in Massachusetts, USA. Freshwater Biology, 36, 731-744. https://doi.org/10.1046/j.1365-2427.1996.00124.x

[23] Stallsmith, B.W. (1995) The Effects of Acid Rain on Lepomis Reproduction in Two Ponds. Ph.D. Dissertation, University of Massachusetts Boston, Boston.

[24] Scott, W.B. and Crossman, E.J. (1973) Freshwater Fishes of Canada. Bulletin of the Fisheries Research Board of Canada, 184, 966 p.

[25] Lee, D.S., Gilbert, C.R., Hocutt, C.H., Jenkins, R.E., McAllister, D.E. and Stauffer Jr., J.R. (1980) Atlas of North American Freshwater Fishes. North Carolina State Museum of Natural History.

[26] Hubbs, C.L. and Hubbs, L.C. (1933) The Increased Growth, Predominant Maleness, and Apparent Infertility of Hybrid Sunfishes. Papers of the Michigan Academy of Science, 17, 613-641.

[27] Childers, W.F. (1971) Hybridization of Fishes in North America (Family Centrarchidae). Representative FAO/UNDP(TA), 2926, 133-142.

[28] Zigler, S.J. and Jennings, C.A. (1993) Growth and Mortality of Larval Sunfishes in Backwaters of the Upper Mississippi River. Transactions of the American Fisheries Society, 122, 1080-1087. https://doi.org/10.1577/1548-8659(1993)122<1080:GAMOLS >2.3.CO;2

[29] Mittelbach, G.G. (1984) Predation and Resource Partitioning in Two Sunfishes (Centrarchidae). Ecology, 65, 499-513. https://doi.org/10.2307/1941412

[30] Palmer, R.E., Klauda, R.J. and Lewis, T.E. (1988) Comparative Sensitivities of Bluegill, Channel Catfish and Fathead Minnow to $\mathrm{pH}$ and Aluminum. Environmental Toxicology and Chemistry, 7, 505-516. https://doi.org/10.1002/etc.5620070610

[31] Hagar, W.G., Crosby, B. and Stallsmith, B. (2000) Comparing and Assessing Acid Rain Sensitive Ponds. Journal of Hazardous Material, 74, 125-131. https://doi.org/10.1016/S0304-3894(99)00203-4

[32] Baker, J.P. and Schofield, C.L. (1982) Aluminum Toxicity to Fish in Acidic Waters. Water, Air, and Soil Pollution, 18, 289-309. https://doi.org/10.1007/BF02419419

[33] Malcolm, I.A., Bacon, P.J., Middlemas, S.J., Fryer, R.J., Shilland, E.M. and Collen, P. (2014) Relationship between Hydrochemistry and the Presence of Juvenile Brown Trout (Salmo trutta) in Headwater Streams Recovering from Acidification. Ecological Indicators, 37, 351-364. https://doi.org/10.1016/j.ecolind.2012.02.029

[34] Delonay, A.J., Little, E.E., Woodward, D.F., Brumbaugh, W.G., Farag, A.M. and Rabeni, C.F. (1993) Sensitivity of Early-Life-Stage Golden Trout to Low pH and Elevated Aluminum. Environmental Toxicology and Chemistry, 12, 1223-1232. https://doi.org/10.1002/etc.5620120711

[35] Ormerod, S.J., Boole, P., McCahon, C.P., Weatherley, N.S., Pascoe, D. and Edwards, R.W. (1987) Short-Term Experimental Acidification of a Welsh Stream: Comparing the Biological Effects of Hydrogen Ions and Aluminium. Freshwater Biology, 17, 341-325. https://doi.org/10.1111/j.1365-2427.1987.tb01054.x

[36] Bil'ko, V.P. (1998) The Effect of pH on the Fish Eggs at Various Stages of Their Development. Hydrobiological Journal, 34, 40-45.

https://doi.org/10.1615/HydrobJ.v34.i1.60 
[37] Jellyman, P.G. and Harding, J.S. (2014) Variable Survival across Low pH Gradients in Freshwater Fish Species. Journal of Fish Biology, 85, 1746-1752. https://doi.org/10.1111/jfb.12497

[38] Geffen, A.J. (1990) Response of Rainbow Smelt, Osmerus mordax (Mitchill), Eggs to Low pH. Journal of Fish Biology, 37, 865-871. https://doi.org/10.1111/j.1095-8649.1990.tb03590.x

[39] Sayer, M.D.J., Reader, J.P. and Dalziel, T.R.K. (1993) Freshwater Acidification: Effects on the Early Life Stages of Fish. Reviews in Fish Biology and Fisheries, 3, 95-132. https://doi.org/10.1007/BF00045228

[40] Reader, J.P., Dalziel, T.R.K., Morris, R., Sayer, M.D.J. and Dempsey, C.H. (1991) Episodic Exposure to Acid and Aluminum in Soft Water: Survival and Recovery of Brown Trout, Salmo trutta L. Journal of Fish Biology, 2, 181-196.

https://doi.org/10.1111/j.1095-8649.1991.tb04355.x

[41] Serrano, I., Buffam, I., Palm, D., Brännäs, E. and Laudon, H. (2008) Thresholds for Survival of Brown Trout during the Spring Flood Acid Pulse in Streams High in Dissolved Organic Carbon. Transactions of the American Fisheries Society, 137, 1363-1377. https://doi.org/10.1577/T07-069.1 